\title{
Diffusion of innovation theory: Beyond decision stage
}

\author{
Muhammad Farooq Tariq ${ }^{1, *}$, Faizuniah Pangil ${ }^{1}$, Arfan Shahzad ${ }^{2}$ \\ ${ }^{1}$ School of Business Management, Universiti Utara Malaysia, Kedah, Malaysia \\ 2Othman Yeop Abdullah Graduate School of Business, Universiti Utara Malaysia, Kedah, Malaysia
}

\section{ARTICLE INFO}

\section{Article history:}

Received 14 December 2016

Received in revised form

27 February 2017

Accepted 15 March 2017

\section{Keywords:}

HRIS

HRIS implementation

IT infrastructure

IT expertise

HR practices

Competitive pressure

\begin{abstract}
A B S T R A C T
This paper has focused on the importance of human resource information system (HRIS) implementation in the organization to achieve the competitive advantage. This study proposed a research framework which is derived from diffusion of innovation (DOI) theory and technological, organizational, and environmental (TOE) framework. For the purpose of this study various determinants that could influence the adoption of HRIS such as IT infrastructure, IT expertise, financial readiness, HR practices and competitive pressure have been evaluated. A proposed methodology is established in the paper which could assist futuristic researchers who are willing to pursue their study in similar context. Previous studies had focused the process of HRIS adoption at decision stage (stage 3 of adoption process in DOI) as dichotomous scale though none of the studies have developed the scale for HRIS implementation (stage 4 of adoption process in DOI). Along with identification of literature gap, this study has also exhibited theoretical and practical implications with regard to HRIS adoption.
\end{abstract}

(C) 2017 The Authors. Published by IASE. This is an open access article under the CC BY-NC-ND license (http://creativecommons.org/licenses/by-nc-nd/4.0/).

\section{Introduction}

Information systems (IS) evolved out to be the spine of the organizations. By utilizing these systems at the operational level processes such as Human Resource Systems, Accounting/ Finance systems, Production/ Manufacturing Systems and Marketing/Sales systems etc., in the organizations could be performed effectively and efficiently. Due to accelerated growth of information technology, organizational IS has also evolved tremendously. Laudon and Laudon (2011) highlighted that organizations are investing heavily on their IS for various purposes such as safeguarding organizational survival, attaining competitive advantage, refining decision making, attaining customer service and trust, developing innovative products and services and achieving operational effectiveness (agility, efficiency, productivity). In short, good information system is highly important for organizational performance.

In this competitive world, organizations cannot lead the business world without using information systems. Therefore, most organizations spent a large sum of money on Information Technology (IT) and

\footnotetext{
* Corresponding Author

Email Address: farooqtariqbutt@gmail.com (M. F. Tariq) https://doi.org/10.21833/ijaas.2017.05.002

2313-626X/C 2017 The Authors. Published by IASE.

This is an open access article under the CC BY-NC-ND license

(http://creativecommons.org/licenses/by-nc-nd/4.0/)
}

Information Systems (IS) with the expectation that it will help them to be a market leader and to gain a competitive advantage (Tansley et al., 2001). Information systems are very crucial for managers as it provide ample important reports to low and middle level managers which support them in decision making. Nowduril and Al-Dossary (2012) asserted that information systems help managers in predicting the future growth of the organizations by providing them with various technical performance analyses. Most importantly, it enables the managers to acquire the information at the right time, and in the right format. In the nutshell, the key goal of information system is to assist an organization to attain its vision by helping the managers to comprehend the systematic function of the organization so that they could plan, manage and monitor the activities more efficiently and effectively.

Every business organization has the heaps of data, which is the lifeblood of today's organization. The human resource (HR) department is the keeper of employee's data. Although over time the means of data keeping has changed and will continue to change, the need to collect such data has not altered yet. The biggest challenge, an organization is facing now a days, is to manage that data and to infer the information from it effectively and efficiently.

In the HR domain, IS has played a vital role in elevating the human resource information system (HRIS). Thite and Kavanagh (2009) defined HRIS as a 
system, which is used to acquire, store, manipulate, retrieve and distribute pertinent information about an organization's human resources. The escalated growth of technology, has improved the capability of HRIS, which made it much easier to manage workers data. As a result, the effectiveness of the overall HR activities has improved immensely. Nevertheless, it also creates a challenge for the HR managers to be aware of new technologies.

The practices in human resource management (HRM) are progressing day by day along with the changing need of today's human resources. Many organizations are learning to use both its assets, specifically human resources and information system, as a strategic instrument to compete (Jenkins and Lloyd, 1985). Using these two assets, human resource management (HRM) is entering into the new era (Lin, 1997) and with the help of human resource information system (HRIS); HRM becomes more effective and efficient. HRIS support different HRM activities such as developing employee training programs in order to improve their skills and talents, maintaining record of existing staffs and assessing performance of potential workers. HRIS also helps senior management in determining manpower requirement to meet the organizations long term strategic plans and goals. HRIS assists middle level managers in the allocation of compensation and benefit to all employees as well as analyze and monitor their performance. HRIS also provide benefits to operational management in placement and requirement of workers. According to Powell and Dent-Micallef (1997), the human resource management in a firm helps in achieving and sustaining competitive advantage only when it is adequately utilized, maintained and deployed.

However, surviving in this modern business world means organizations must maintain and utilize the optimum level of organizational resource, using different tools and technologies. To utilize the human capital efficiently and effectively, HRIS is the required tool and technology. Organizational performance and success depends on efficiency and effectiveness of HR (Lippert and Swiercz, 2005), however appropriate HRM is the key to achieve efficiency and effectiveness from organizational HR. Ball (2001) conducted a study on Fortune 500 firms and found that almost 60 percent of these firms are utilizing human resource information systems (HRIS) to efficiently execute their HRM functions. According to Al-Mamary and Shamsuddin (2014), HRIS has helped companies to transform HRM into mechanization which saves resources, costs and time. In short, HRIS assists in improving organizational workflow and managing employees' data which eventually improve customer satisfaction and employee productivity.

Indeed, there are numerous advantages that IS provide to an organization in context of managing human resource, including management of daily HR activities, enhancement in departmental and organizational techniques, reduction of excess staff, access to adequate and necessary information, the means of efficient and effective communication among various organizational levels and eventually bring adequate responses to a business situation to. The development of HRIS has helped the organizations to gain competitive advantage due to better and more efficient HRM (Powell and DentMicallef, 1997). In fact, in present competitive world, effective use of IS in HRM helps organizations in gaining desired objectives which ultimately leads to success (Zhang and Wang, 2006).

However, HRIS is only helpful for the organization if it is implemented at full scale as an integrated system. An integrated HRIS is one which is encapsulating all the functions of HR department and sharing the information among all the applications of HRIS. The speedy growth of IT has evolved the paper based systems into the computerized automated systems. In this $21^{\text {st }}$ century, only a computerized HRIS system could be the strategic partner of the organization instead of piles of files and registers kept in HR departments or store rooms. Organizational performance and success depends on efficiency and effectiveness of HR (Lippert and Swiercz, 2005), however appropriate implementation of HRIS is the key to achieve efficiency and effectiveness. A computerized HRIS could provide the required information on a single click, which saves time and cost, and also increases the efficiency and effectiveness of department.

Due to the importance of HRIS in organizations, researchers in the area of management and IS alike has focus their attention on understanding this system and the factors that affects the decision of adopting innovations, like HRIS. Whereas, factors that helps organizations to implement HRIS are still not investigated and the findings of existing research are not comprehensive and might be a little misleading because the scale that were used to measure HRIS implementation were too simplified.

In essence, HRIS is an integrated system of multiple applications. However, most current studies only measure the number of hours and number of times HRIS is used (Kassim et al., 2012). In doing so, the study could not capture the level of implementation of HRIS. This scale of measuring hours and times also does not portrays which applications of HRIS is under use and which of them are not. Even if the respondent indicates usage, zero hours, that does not tells ether they have system or not. An organization may be using only one or few applications of HRIS, whereas HRIS is an integrated system of many applications, in that case HRIS could not be the strategic partner of the organization and will not be able to support in decision making. Therefore, there should be a scale that really measures all the aspects of HRIS adoption at implementation level.

Hence, the primary objective of this paper is to discuss the process in developing a scale that could measure the implementation of the HRIS in organizations. In previous studies (Chau and Tam, 1997; Kuan and Chau, 2001; Zhu et al., 2003; Teo et 
al., 2007; Oliveira and Martins, 2008; Lee et al., 2009; Ghobakhloo et al., 2011) various method have been used to measure IS adoption. However, the scale used was inadequate in measuring the adoption of HRIS at implementation stage. Therefore, an empirical study is needed that aims to the process of identifying the best way to measure HRIS adoption based on the five stages of diffusion of innovation theory. Along with that this study aims to determine the impact of IT infrastructure, IT expertise, financial readiness, HR practices, and competitive pressure on organizational implementation of HRIS.

\section{Literature review and hypothesis development}

Previously researchers (Thong, 1999; Zhu et al., 2006; Chong et al., 2009; Wang et al., 2010) have identified many variables, using the DOI and TOE that can impact the adoption decision of IT innovation behavior in an organization. Some authors have built conceptual model and some have evaluated empirical studies in this perspective. However, the previous studies have mainly focused the different IT innovations (Material Requirement Planning, Internet, website, e-commerce, and ERP etc.) at organizational level. Authors like Oliveira and Martins (2008), Kuan and Chau (2001), and Hsu et al. (2006) studied these variables for website or ecommerce adoption. However, results of these studies shows that for each type of IT adoption variables may differ under these factors. These variables can be segregated into three different contexts i.e. technological, organizational and environmental.

\subsection{Diffusion of innovation}

HRIS is an innovation that could be beneficial to organizations in managing their human resources. Like any other innovations, the diffusion of HRIS in organizations can be explained based on the Diffusion of Innovation (DOI) theory. In other words, HRIS are diffused in organizations at different levels according to the characteristics of innovation and organization. Based on DOI, the process of innovation adoption is a five stage process: 1) knowledge, 2) persuasion, 3) decision, 4) implementation, and 5) confirmation (Rogers, 1983). Knowledge is the first stage and the importance of knowledge in today's complex global environment cannot be ignored (Jamshidi, 2015; Avazzadeh, 2015). Bases on knowledge persuasion take place and then decisions are made. Previous studies in the area of IS (Zhu et al., 2003; Oliveira and Martins, 2008; Pan and Jang, 2008; Ghobakhloo et al., 2011), have studied many kind of IS adoptions like website, e-business, e-commerce, ERP, marketing etc., but studies focus on HRIS are still lacking particularly one that measures HRIS adoption. Researchers have identified many factors that affect the decision of adoption. Furthermore, most of these studies measure adoption only at the decision stage. Whereas, the need of the time is to study the adoption process beyond the decision stage i.e. the implementation stage. However, the benefits of HRIS could only be reaped out after the organizations implements HRIS, not by only decision to use. Hence, understanding HRIS adoption is of high importance.

\subsection{Adoption of HRIS}

Concerning adoption, current study focuses on the organizational level. In organizations, adoption process comprises several stages. Rogers and Singhal (2003) suggested that initiation and implementation can be seen as major stages of adoption. Nevertheless, Zhu and Kraemer, (2005) highlighted that instead of focusing on implementation, many previous researchers focused on the adoption decision. Some studies focused on the extent of use of HRIS and measure it by the number of times and hours HRIS used per week (Kassim et al., 2012). It should be noted that HRIS is a full fledge integrated system of multiple applications (such as payroll administration, attendance, recruitment and selection, employee data, training and development, compensation and benefits management, performance appraisal and HR planning) by only measuring the number of hours and number of times HRIS is used, cannot depicts the level of implementation of HRIS. This scale of measuring hours and times also does not portrays which applications (such as payroll administration, attendance, HR planning, performance appraisal, benefits and compensation management, recruitment and selection and employee data) of HRIS is under use and which of them are not.

Furthermore, there is difference between cumulative adoption and cumulative deployment after initial acquisition. Some researchers (Eveland and Tornatzky, 1990) also have pointed out occasions of either under-utilization or deinstallation of recently installed technologies after initial acquisition. Regardless, there is a gap in existing literature to measure the adoption of HRIS at fourth (implementation) stage of adoption process. For this study adoption of HRIS is conceptualized as "implementing a computerized and integrated information system (comprised of applications, such as payroll administration, attendance, HR planning, performance appraisal, benefits and compensation management, recruitment and selection and employee data) which is used to acquire, store, manipulate, retrieve and distribute relevant information about an organization's human resources at organizational level to perform HR activities".

\subsection{IT infrastructure}

First factor suggested in the present study's framework under the technological contexts is IT infrastructure. IT infrastructure of any organization consists of the hardware, software, database and telecommunications that are required to operate in 
the organization. It is the IT infrastructure on which the building of IS based.

Pan and Jang (2008) found IT infrastructure as insignificant when it comes to ERP adoption in Taiwan. On the other hand presence of IT infrastructure influenced the adoption of ecommerce innovation (Gibbs and Kraemer, 2004). $\mathrm{Hsu}$ et al. (2006) reported significantly positive effect on the adoption of e-business innovation. Moreover, some other researchers (Zhu et al., 2006; Hadaya, 2008; Fink and Neumann, 2009; Oliveira and Martins, 2010; Al-Mobaideen et al., 2013) found IT infrastructure has a positive and significant effect on adoption of different IT innovation. Hence in the context of HRIS first hypothesis can be concluded as:

H1: There is a positive significant relationship between IT infrastructure and adoption of HRIS.

\subsection{IT expertise}

Second technological factor effecting the IT adoption is IT expertise. It relates with the employees' knowledge and skills of using computers in the organization. HRIS can only be adopted if the employees have good IT expertise because it is the large factor in the adoption of HRIS (Rand et al., 2013).

Teo et al. (2006) pinpointed that the lack of IT expertise as an inhibitors of B2B e-commerce adoption in North America and Canada. Based on his finding he confirmed that IT expertise has positive significant effect on the adopting e-commerce. Such results are also found by some recent studies in other disciplines of the IT adoption (Lin and Lin, 2008; Soares-Aguiar and Palmados-Reis, 2008; Lee et al., 2009; Martins and Oliveira, 2009). Being an important factor, IT expertise will be studied as a technological factor of HRIS adoption in this study. Hence the second hypothesis is established as:

$\mathrm{H} 2$ : There is a positive significant relationship between IT expertise and adoption of HRIS.

\subsection{Financial readiness}

Under the organizational contexts financial readiness is the utmost central factor. Financial readiness means the financial resources available to adopt an innovation. The most important resource in any organization is the financial one. No matter, how necessary an innovation is for the organization, if the organization does not have financial resources innovation cannot be adopted. The financial readiness variable is used to measure whether an organization is ready to pay the cost of HRIS or not.

Kuan and Chau (2001) found organizations with financial readiness are more likely to adopt electronic data interchange (EDI) which is consistent with findings of Iacovou et al. (1995) suggested that financial readiness as an influencing factor in adoption of IT. Camilla and Nils (2004) also reported that a high influence of financial resources on the IT adoption in their study at Volvo. Few studies (Mehrtens et al., 2001; Chan and Mills, 2002) found a non-significant relationship between financial readiness and adoption of IT. The inconsistent results of previous studies compel to conclude third hypothesis in this study as:

H3: There is a significant relationship between financial readiness and adoption of HRIS.

\subsection{HR practices}

The second factor suggested in this model, under the organizational contexts, is HR practices. HR practices are applied in recruitment and selection, training, performance appraisal, compensation and benefits, higher promotional opportunity, and rewards system. In diagnosing HR problems, competition and best utilization of resources have pushed organizations to be proactive and adopt more innovative $\mathrm{HR}$ practices, rather than reactive (Agarwala, 2003).

Several studies (Arthur, 1994; Huselid, 1995; MacDuffie, 1995; Delery and Doty, 1996; Guthrie, 2001; Wright et al., 2005) concluded that HR practices and performance of the organization have positive relationship. The key objective of computerization of the organization is to enhance the organization's performance. Some recent studies (Chong et al., 2009; Oliveira and Martins, 2010) reveal the fact that relative advantage and perceived usefulness are the key determinants of the innovation adoption. According to (Agarwala, 2003) using innovative HR practices is no longer a matter of trend but necessity. The organizations practicing HR bundle in traditional ways may tends more towards the adoption of HRIS. Hence, the fourth hypothesis for HR practices in context of adoption of HRIS can be established as:

H4: There is a significant relationship between HR practices and adoption of HRIS.

\subsection{Competitive pressure}

In environmental context, competitive pressure is the most important factor in the adoption of innovations. Some researchers (Sadowski et al., 2002; Beveren and Thomson, 2002; Scupola, 2003; Zhu et al., 2003; Gibbs and Kraemer, 2004) come up with the empirical evidence and found competitive pressure as a powerful driver of IT innovation adoption. Contrary to that Teo (2007) did not found competitive pressure as a significant factor for the adoption of innovation. This difference may be the result of different kind of IT adoption. Now as days, due to latest and fast communication links and internets, world has been converted into a global village. As organizations are striving for the best utilization of resources to compete the international markets. Consequently the real pressure comes to the HR department to formalize the best practices to utilize the human capital at its maximum, effectively and efficiently. HRIS is the latest tool to cop up with such HR challenges. Hence fifth hypothesis for competitive pressure is determined as: 
H5: There is a significant relationship between competitive pressure and adoption of HRIS.

\section{Proposed methodology}

This research will employee the mix method approach and the study will be divided into two phases as illustrated in Fig. 1. Using qualitative method, phase one will develop a new construct for the measurement of implementation of HRIS in organizations. Using quantitative method, phase two will (using the newly developed construct in phase one) examine the factors effecting the implementation of HRIS in organizations.

In Phase 1, the first stage of the scale development process will involve defining the conceptual domain of the construct. Based on the literature in this study researcher will conceptualize the definition of implementation of HRIS. The next step in the process will to generate a set of items that fully represents the conceptual domain of the construct.

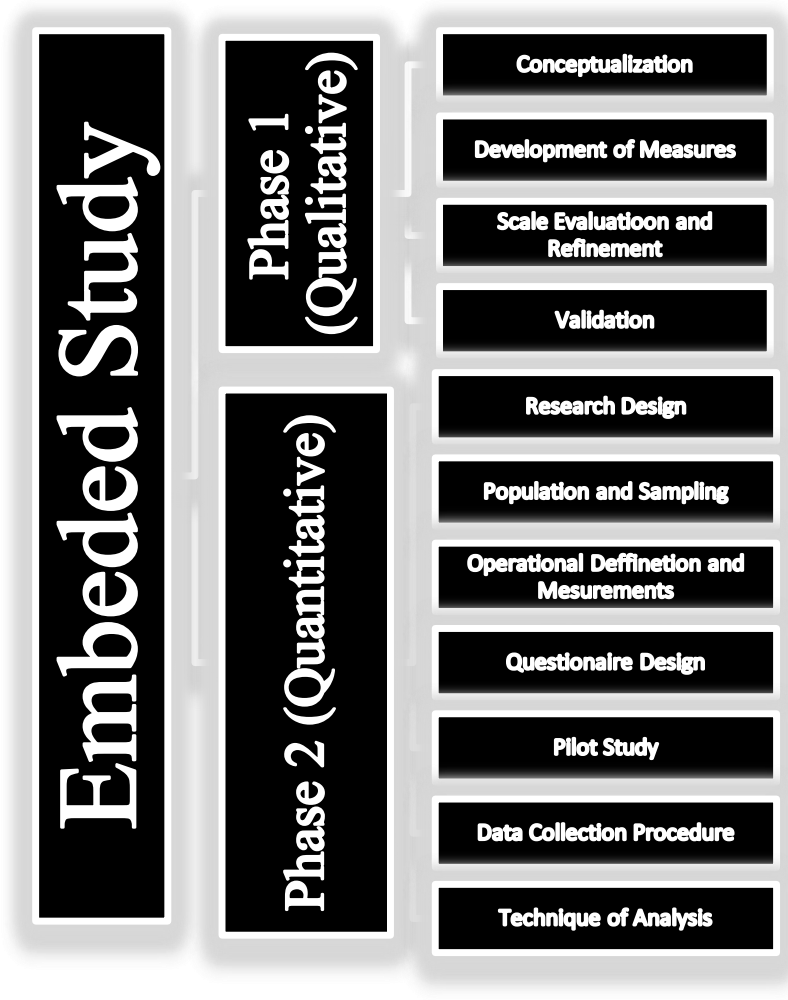

Fig. 1: Proposed methodology of the study

Once items will be generated for representing the focal construct, they would be evaluated for their face and content validity. Once the measurement model has been formally specified, data will be obtained from a sample of respondents in order to examine the psychometric properties of the scale, and to evaluate its convergent, discriminant, and nomological validity. In case, the items will be added, dropped, and reworded in the scale purification process, the next step will be to re-estimate the new sample of the data for the validation. If the reliability of the instrument will below expectation then the present study will do the re-estimation.
In phase 2, the newly developed items will be tested. For this purpose, variables that have been found to positively affect HRIS adoption will be used to determine the stability of the items. Hence, variables such as IT infrastructure (Zhu et al., 2006; Hadaya, 2008; Fink and Neumann, 2009; Oliveira and Martins, 2010; Al-Mobaideen et al., 2013), IT expertise (Lin and Lin, 2008; Soares-Aguiar and Palmados-Reis, 2008; Lee et al., 2009; Martins and Oliveira, 2009), financial readiness (Kuan and Chau, 2001; Iacovou et al., 1995), HR practices (Agarwala, 2003), and competitive pressure (Sadowski et al., 2002; Beveren and Thomson, 2002; Scupola, 2003; Zhu et al., 2003; Gibbs and Kraemer, 2004) will be correlated with HRIS adoption measure.

For Phase 2, the unit of analysis will be the organization and the respondents will the head of HR department, representing their organization. Population will depend on where the research would be conducted and sample will be chosen accordingly. Measurement scale of Independent variables already exists and the scale of dependent variable will be developed in phase 1 of the study. Using these scales a questionnaire will be designed for the organizations using HIRS. By distributing the questionnaires response will be collected and after the analysis empirical prove would be established for the phase 2 .

\section{Conclusion and feature research}

HR is one of the most important departments of any organization. It supports all other departments and fulfills their human capital needs along with necessary trainings and skills. HR department is the backbone of the modern word organization. This department is custodian of all the data related to the employees of the organization. Information systems are the tools to manage this data. Here come the Human resource information systems. By the advancement of IT information systems are much quicker and efficient than ever before. Modern world HRIS are the computerized systems used to manage all the activities of HR department. These HRIS made HR department as a strategic partner of the organization.

An integrated computerized HRIS is the innovation of the current era. Innovation adoption in the organizations is a five stage process defined by Rogers (1983). Previous studies have focused on the factors affecting the decision of adoption (third stage of adoption process). Now, it is the time to move ahead and to develop a scale to measure the implementation (fourth stage of the adoption process). Because many organizations are now using HRIS but don't know either they are using it up to full potential or underutilizing it.

Therefore, this study demands to conduct a qualitative study for the scale development of HRIS implementation followed by a quantitative study to validate this HRIS implementation scale. In future longitudinal studies should conduct, to highlight the 
barriers and benefits, before and after implementation of HRIS.

\section{References}

Agarwala $\mathrm{T}$ (2003). Innovative human resource practices and organizational commitment: An empirical investigation. International Journal of Human Resource Management, 14(2): 175-197.

Al-Mamary YH and Shamsuddin A (2014). The meaning of management information systems and its role in telecommunication companies in Yemen. American Journal of Software Engineering, 2(2): 22-25.

Al-Mobaideen H, Allahawiah S, and Basioni E (2013). Factors influencing the successful adoption of human resource information system: The content of Aqaba special economic zone authority. Intelligent Information Management, 5(1): 1 9.

Arthur JB (1994). Effects of human resource systems on manufacturing performance and turnover. Academy of Management Journal, 37(3): 670-687.

Avazzadeh E (2015). Investigation the effect of customer relationship management on customer's loyalty and satisfaction (case study: Shiraz city Refah chain stores). International journal of Advanced and Applied Sciences, 2(2): 11-15.

Ball KS (2001). The use of human resource information systems: a survey. Personnel Review, 30(6): 677-693.

Beveren VJ and Thomson H (2002). The use of electronic commerce by SMEs in Victoria, Australia. Journal of Small Business Management, 40(3): 250-253.

Camilla R and Nils L (2004). Exploring critical success factors in adopting new technology. M.Sc. Thesis, Luleå University of Technology, Luleå, Sweden.

Chan P and Mills A (2002). Motivators and inhibitors of ecommerce technology adoption: Online stock trading by small brokerage firms in New Zealand. Journal of Information Technology Case and Application Research, 4(3): 38-56.

Chau PY and Tam KY (1997). Factors affecting the adoption of open systems: an exploratory study. MIS Quarterly, 21(1): 124.

Chong AYL, Ooi KB, Lin BS, and Raman M (2009). Factors affecting the adoption level of c-commerce: An empirical study. Journal of Computer Information Systems, 50(2):13-22.

Delery JE and Doty DH (1996). Modes of theorizing in strategic human resource management: Tests of universalistic, contingency, and configurational performance predictions. Academy of management Journal, 39(4): 802-835.

Eveland JD and Tornatzky LG (1990). The deployment of technology. In: Tornatzky LG and Fleischer M (Eds.), The processes of technological innovation: 117-148. Lexington Books, Maryland, Massachusetts, USA.

Fink L and Neumann S (2009). Exploring the perceived business value of the flexibility enabled by information technology infrastructure. Information and Management, 46(2): 90-99.

Ghobakhloo M, Arias-Aranda D, and Benitez-Amado J (2011) Adoption of e-commerce applications in SMEs. Industrial Management and Data Systems, 111(8): 1238-1269.

Gibbs LJ and Kraemer KL (2004). A cross-country investigation of the determinants of scope of e-commerce use: An institutional approach. Electronic Markets, 14(2): 124-137.

Guthrie JP (2001). High-involvement work practices, turnover, and productivity: Evidence from New Zealand. Academy of Management Journal, 44(1): 180-190.
Hadaya P (2008), Determinants and performance Outcome of SMEs' use of vertical B-to-B e-marketplaces to sell products. Electronic Markets, 18(3): 260-274.

Hsu PF, Kraemer KL, and Dunkle D (2006). Determinants of ebusiness use in us firms. International Journal of Electronic Commerce, 10(4): 9-45.

Huselid MA (1995). The impact of human resource management practices on turnover, productivity, and corporate financial performance. Academy of Management Journal, 38(3): 635672.

Iacovou CL, Benbasat L, and Dexter AS. (1995). Electronic data interchange and small organizations: Adoption and impact of technology. MIS Quarterly, 19(4): 465-485.

Jamshidi AA (2015). A survey of the relationship between knowledge storage and web-based learning in students. International Journal of Advanced and Applied Sciences, 2(11): 94-98.

Jenkins ML and Lloyd G (1985). How corporate philosophy and strategy shape the use of HR information systems. Personnel, 62(5): 28-38.

Kassim NM, Ramayah T, and Kurnia S (2012). Antecedents and outcomes of human resource information system (HRIS) use. International Journal of Productivity and Performance Management, 61(6): 603-623.

Kuan KK and Chau PY (2001). A perception-based model for EDI adoption in small businesses using a technologyorganization-environment framework. Information and Management, 38(8): 507-521.

Laudon KC and Laudon JP (2011). Management information systems. Prentice Hall, New Jersey. USA.

Lee OK, Wang M, Lim KH, and Peng Z (2009) Knowledge management systems diffusion in chinese enterprises: A multistage approach using the technology-organizationenvironment framework. Journal of Global Information Management, 17(1): 70-84.

Lin CYY (1997). Human resource information systems: Implementation in Taiwan. Research and Practice in Human Resource Management, 5(1): 57-72.

Lin HF and Lin SM (2008). Determinants of e-business diffusion: A test of the technology diffusion perspective. Technovation, 28(3): 135-145.

Lippert SK and Swiercz PM (2005). Human resource information systems (HRIS) and technology trust. Journal of Information Science, 31(5): 340-353.

MacDuffie JP (1995). Human resource bundles and manufacturing performance: Organizational logic and flexible production systems in the world auto industry. Industrial and Labor Relations Review, 48(2): 197-221.

Martins M and Oliveira T (2009). Determinants of e-commerce adoption by small firms in portugal. In the $3^{\text {rd }}$ European Conference on Information Management and Evaluation, ECISM, Gothenburg, Sweden: 328-338.

Mehrtens J, Crag PB, and Mills AM (2001). A model of internet adoption by SMEs. Information and Management, 39(3): 165176.

Nowduril S and Al-Dossary S (2012). Management information systems and its support to sustainable small and medium enterprises. International Journal of Business and Management, 7(19): 125-131.

Oliveira T and Martins MF (2010). Understanding e-business adoption across industries in European countries. Industrial Management and Data System, 110(9): 1337-1354.

Oliveira T and Martins MFO (2008). A comparison of web site adoption in small and large portuguese firms. In the International Conference on E-business (ICE-B 2008), ICE-B, Porto, Portugal: 370-377. 
Pan MJ and Jang WY (2008). Determinants of the adoption of enterprise resource planning within the technologyorganization-environment framework: Taiwan's communications industry. Journal of Computer Information Systems, 48(3): 94-102.

Powell TC and Dent-Micallef A (1997). Information technology as competitive advantage: The role of human, business, and technology resources. Strategic Management Journal, 18(5): 375-405.

Rand HAD, Steve L, and Al-Zu'bi ZM (2013). Factors influencing the adoption of HRIS applications: A literature review. International Journal of Management and Business Studies, 3(4): 9-26.

Rogers EM (1983). Diffusion of innovations. $3^{\text {rd }}$ Edition, The Free Press, New York, USA.

Rogers EM and Singhal A (2003). Empowerment and communication: Lessons learned from organizing for social change. Annals of the International Communication Association, 27(1): 67-85.

Sadowski BM, Maitland C, and van Dongen J (2002). Strategic use of the internet by small-and medium-sized companies: An exploratory study. Information Economics and Policy, 14(1): 75-93.

Scupola A (2003). Government intervention in SMEs e-commerce adoption: An institutional approach. In the $7^{\text {th }}$ Asia Conference on Information Systems, IGI Global, Adilade, South Australia: 158-178.

Soares-Aguiar A and Palmados-Reis A (2008). Why do firms adopt e-procurement systems? Using logistic regression to empirically test a conceptual model. IEEE Transactions on Engineering Management, 55(1): 120-133.

Tansley C, Newell S, and Williams H (2001). Effecting HRM-style practices through an integrated human resource information system: An e-greenfield site?. Personnel Review, 30(3): 351371.

Teo TS, Lim GS, and Fedric SA (2007). The adoption and diffusion of human resources information systems in Singapore. Asia Pacific Journal of Human Resources, 45(1): 44-62.
Teo TS, Ranganathan C, and Dhaliwal J (2006). Key dimensions of inhibitors for the deployment of web-based business-tobusiness electronic commerce. IEEE Transactions on Engineering Management, 53(3): 395-411.

Teo TSH (2007). Organizational characteristics, modes of internet adoption and their impact: A Singapore perspective. Journal of Global Information Management, 15(2): 91-117.

Thite M and Kavanagh M (2009). Evolution of human resource management and human resource information systems: the role of information technology. In: Kavanagh $\mathrm{M}$ and Thite $\mathrm{M}$ (Eds.), Human resource information systems: Basics, applications and future directions: 3-24. Sage, Thousand Oaks, USA.

Thong JY (1999). An integrated model of information systems adoption in small businesses. Journal of Management Information Systems, 15(4): 187-214.

Wang YM, Wang YS, and Yang YF (2010). Understanding the determinants of RFID adoption in the manufacturing industry. Technological Forecasting and Social Change, 77(5): 803-815.

Wright PM, Gardner TM, Moynihan LM, and Allen MR (2005). The relationship between HR practices and firm performance: Examining causal order. Personnel Psychology, 58(2): 409446.

Zhang L and Wang H (2006). Intelligent information processing in human resource management: an implementation case in China. Expert Systems, 23(5): 356-369.

Zhu K and Kraemer KL (2005). Post-adoption variations in usage and value of e-business by organizations: cross-country evidence from the retail industry. Information Systems Research, 16(1): 61-84.

Zhu K, Dong ST, Xu SX, and Kraemer KL (2006) Innovation diffusion in global contexts: Determinants of post-adoption digital transformation of European companies. European Journal of Information Systems, 15(6): 601-616.

Zhu K, Kraemer K, and Xu S (2003). Electronic business adoption by European firms: A cross-country assessment of the facilitators and inhibitors. European Journal of Information Systems, 12(4): 251-268. 